\title{
Developing emergency department physician shift schedules optimized to meet patient demand
}

\author{
David W. Savage, $\mathrm{PhD}^{*}$; Douglas G. Woolford, $\mathrm{PhD}^{\dagger}$; Bruce Weaver, MSc* ; David Wood, MSc, $\mathrm{MD}^{* \ddagger}$
}

\section{ABSTRACT}

Objectives: 1) To assess temporal patterns in historical patient arrival rates in an emergency department (ED) to determine the appropriate number of shift schedules in an acute care area and a fast-track clinic and 2) to determine whether physician scheduling can be improved by aligning physician productivity with patient arrivals using an optimization planning model.

Methods: Historical data were statistically analyzed to determine whether the number of patients arriving at the ED varied by weekday, weekend, or holiday weekend. Poisson-based generalized additive models were used to develop models of patient arrival rate throughout the day. A mathematical programming model was used to produce an optimal ED shift schedule for the estimated patient arrival rates. We compared the current physician schedule to three other scheduling scenarios: 1) a revised schedule produced by the planning model, 2) the revised schedule with an additional acute care physician, and 3 ) the revised schedule with an additional fast-track clinic physician.

Results: Statistical modelling found that patient arrival rates were different for acute care versus fast-track clinics; the patterns in arrivals followed essentially the same daily pattern in the acute care area; and arrival patterns differed on weekdays versus weekends in the fast-track clinic. The planning model reduced the unmet patient demand (i.e., the average number of patients arriving at the ED beyond the average physician productivity) by $19 \%, 39 \%$, and $69 \%$ for the three scenarios examined.

Conclusions: The planning model improved the shift schedules by aligning physician productivity with patient arrivals at the ED.

\section{RÉSUMÉ}

Objectifs: L'étude avait pour objectifs de: 1) évaluer dans le temps, d'après des données historiques, I'affluence des patients dans un service des urgences (SU) afin de déterminer I'horaire de roulement des médecins dans une zone de soins impératifs et dans un service de traitement rapide et
2) déterminer s'il serait possible d'améliorer l'horaire des médecins en adaptant leur productivité à l'affluence des patients selon un modèle d'optimisation de la planification. Méthode: Des données historiques ont fait l'objet d'une analyse statistique afin de déterminer si le nombre de patients arrivant au SU variait selon les jours de la semaine, les fins de semaine, ou les fins de semaine de congé. Nous avons utilisé des modèles additifs généralisés, reposant sur le processus de Poisson, pour élaborer des modèles d'affluence des patients tout le long de la journée. Un modèle mathématique de programmation a servi à élaborer un horaire de roulement optimal au SU en fonction de l'affluence estimée des patients. II y a eu comparaison de l'horaire actuel de travail des médecins avec trois scénarios de roulement: 1) un horaire modifié, produit par le modèle de planification; 2) I'horaire modifié, prévoyant l'ajout d'un médecin dans la zone de soins impératifs; et 3) I'horaire modifié, prévoyant l'ajout d'un médecin au service de traitement rapide.

Résultats: L'analyse a révélé que l'affluence des patients variait selon qu'il s'agissait des soins impératifs ou du traitement rapide; I'affluence était à peu près stable, tous les jours, dans la zone de soins impératifs, tandis que l'affluence variait selon les jours de la semaine ou les fins de semaine au service de traitement rapide. Le modèle de planification a permis de réduire le nombre de demandes non satisfaites (c'est-à-dire le nombre moyen d'arrivées au SU, supérieur à la productivité moyenne des médecins) de $19 \%$, de $39 \%$, et de $69 \%$ dans les trois scénarios étudiés.

Conclusion: Le modèle de planification a permis d'améliorer les horaires de roulement en adaptant la productivité des médecins à I'arrivée des patients au SU.

Keywords: mathematical programming, patient arrivals, patient demand, physician scheduling

In Canada, overcrowding in emergency departments (EDs) is common, occurring when the demand for medical services exceeds the capacity of the ED to

From the *Northern Ontario School of Medicine, Lakehead University, Thunder Bay, ON; †Department of Mathematics, Wilfrid Laurier University, Waterloo, ON; and \#Emergency Department, Thunder Bay Regional Health Sciences Centre, Thunder Bay, ON.

Correspondence to: Dr. David Savage, Northern Ontario School of Medicine, Lakehead University, 955 Oliver Road, Thunder Bay, ON P7B 5E1; dsavage@nosm.ca.

This article has been peer reviewed. 
provide care in a reasonable length of time. ${ }^{1,2}$ Since 2008, the Ontario government has targeted ED wait times as a key priority for service improvement. The total time in the ED is expected to be less than 8 hours for high-acuity patients and less than 4 hours for lowacuity patients. ${ }^{3}$ Overcrowding has a variety of impacts on the ED, including increased wait times, decreased physician productivity, increased likelihood of poor outcomes, decreased patient and provider satisfaction, and extended pain and suffering of patients. ${ }^{4}$ Generally, the interventions to reduce ED overcrowding can be grouped into strategies that affect patient input, throughput, and output. ${ }^{5}$

One strategy to increase patient throughput in the ED is to align staffing with patient arrivals. Much of the current research on ED staffing involves the addition or modification of duties of physician, nurses, and/or clerical staff to increase patient flow. ${ }^{6-12}$ The addition of physician staff in these studies was typically during periods of increased patient arrivals (i.e., evening shifts) in the ED. However, little or no analysis was presented to justify the allocation of the new staff or the current schedule of physicians.

Operations research (OR) typically uses mathematical models to improve decision making related to the allocation of scarce resources with the ultimate goal of improved efficiency. ${ }^{13}$ One OR approach, specifically computer simulation, was used to determine the appropriate staffing levels required to meet length of stay (LOS) and wait time targets in the ED. ${ }^{14,15}$ These staffing levels were then used in a mathematical programming model (i.e., another OR modelling approach) to develop optimal shift schedules. In another study, simulation techniques were used to assess predetermined shift schedules to determine the impact on wait times. ${ }^{16}$ One of the overall conclusions from these studies is that aligning staff scheduling with patient arrivals reduced LOS and wait times.

Unlike several of the studies discussed above, many of the EDs in Ontario determine their physician staffing levels based on an alternative funding agreement that uses historical numbers of patients and their acuity to determine the number of physician hours available to work. ${ }^{17}$ This funding model produces a fixed staffing level that could be scheduled using a mathematical programming approach that would produce optimal schedules that align ED physicians with patient arrivals.
The first objective was to assess the variation in historical patient arrival data from the Thunder Bay Regional Health Sciences Centre (TBRHSC) ED. Temporal patterns in patient arrival rates were quantified to determine whether a single (i.e., patient arrival rates are the same for each day of week) or multiple (i.e., patient arrival rates vary by day of the week) shift schedules would be suitable for an acute care area and a fast-track clinic in the ED. A mixedinteger programming model (i.e., a type of mathematical programming model) was developed to produce an optimal ED physician schedule based on the historical patient arrival data. We then compared the current ED physician schedule to three other scheduling scenarios to quantify the effect of using the planning model. The three scenarios investigated the current staffing level plus the addition of another physician to the ED. The scenarios were 1) a revised schedule produced by the planning model, 2) a revised schedule with an additional acute care area physician, and 3) a revised schedule with an additional fast-track clinic physician.

\section{METHODS}

\section{Description of the TBRHSC ED}

The TBRHSC is a regional referral centre for adult and pediatric patients with approximately 109,000 patients arriving per year at the ED. The ED is organized with both an acute care area for high-acuity patients and a fast-track clinic for lower-acuity patients. Patients classified under the Canadian Trauma and Acuity Scale (CTAS) as 4 and 5 are seen primarily in the fast-track clinic, whereas CTAS 1,2 , and 3 patients are primarily seen in the acute care area. During the study period, physicians, nursing staff, respiratory therapists, physiotherapists, occupational therapists, porters, laboratory technicians, electrocardiography technicians, and a geriatric services staff member were the primary health care providers in the department. Fourth-year medical students and residents are also common in the department, especially throughout the nonsummer months. In January 2013 (i.e., after the data for this study were collected), a physician assistant (PA) was hired to perform initial assessments in a rapid assessment zone associated with the acute care area. The PA is required to consult with the physician on treatment and disposition for all 
patients. Figure 1 shows the estimated arrival rates for the number of patients arriving in the acute care area and the fast-track clinic during each day of the week.

\section{Analysis of patient arrivals at the ED}

The arrival rates in Figure 1 were estimated by fitting generalized additive models (GAMs) to the historical arrival data from the acute care area and fast-track clinics. Given that counts of arrivals (i.e., the total patient arrivals by hour) were modelled, we assumed a Poisson framework. A Poisson GAM is a generalization of a regression model: the observed arrivals were assumed to follow a Poisson process (i.e., a discrete probability distribution) whose arrival rate varies as a function of time. GAMs estimate a curve using a flexible technique; there is no need to specify the mathematical form of the functional relationship in advance of fitting the model. Instead, data observed in small "windows" of time drive the underlying shape of the curve over its range ${ }^{18}$ using penalized spline smoothing methodology, which guards against overor underfitting of the data by controlling the smoothness of the curve. ${ }^{19}$
Several different formulations of Poisson GAMs were fit to both the acute care area and fast-track clinic data sets to assess whether these treatment areas experienced the same patterns in arrival rates, whether rates varied by day or on weekdays versus weekends, and whether there were any changes on holiday weekends. The statistical analyses were completed using the open source $R$ statistical computing software $^{20}$ using functions from the mgcv package. ${ }^{19}$

\section{ED physician schedules}

Currently, a single physician schedule is used for all days of the year with no variation by day of the week or season. In the fast-track clinic, two dedicated physicians see patients during 8 -hour shifts that start at 0800 and 1600 hours. In the acute care area, there are nine daily shifts, which begin at 0700, 0900, 1000, 1300, $1500,1700,1900,2100$, and 2359. Most of these acute care shifts are 8 hours in duration (the 2100 shift is only 6 hours long), with the first 4 hours of each shift dedicated to seeing new patients, writing orders, waiting for diagnostic test results, and reassessing patients. The remaining 4 hours of the shift are used to determine patient disposition (i.e., admitted or discharged). In the

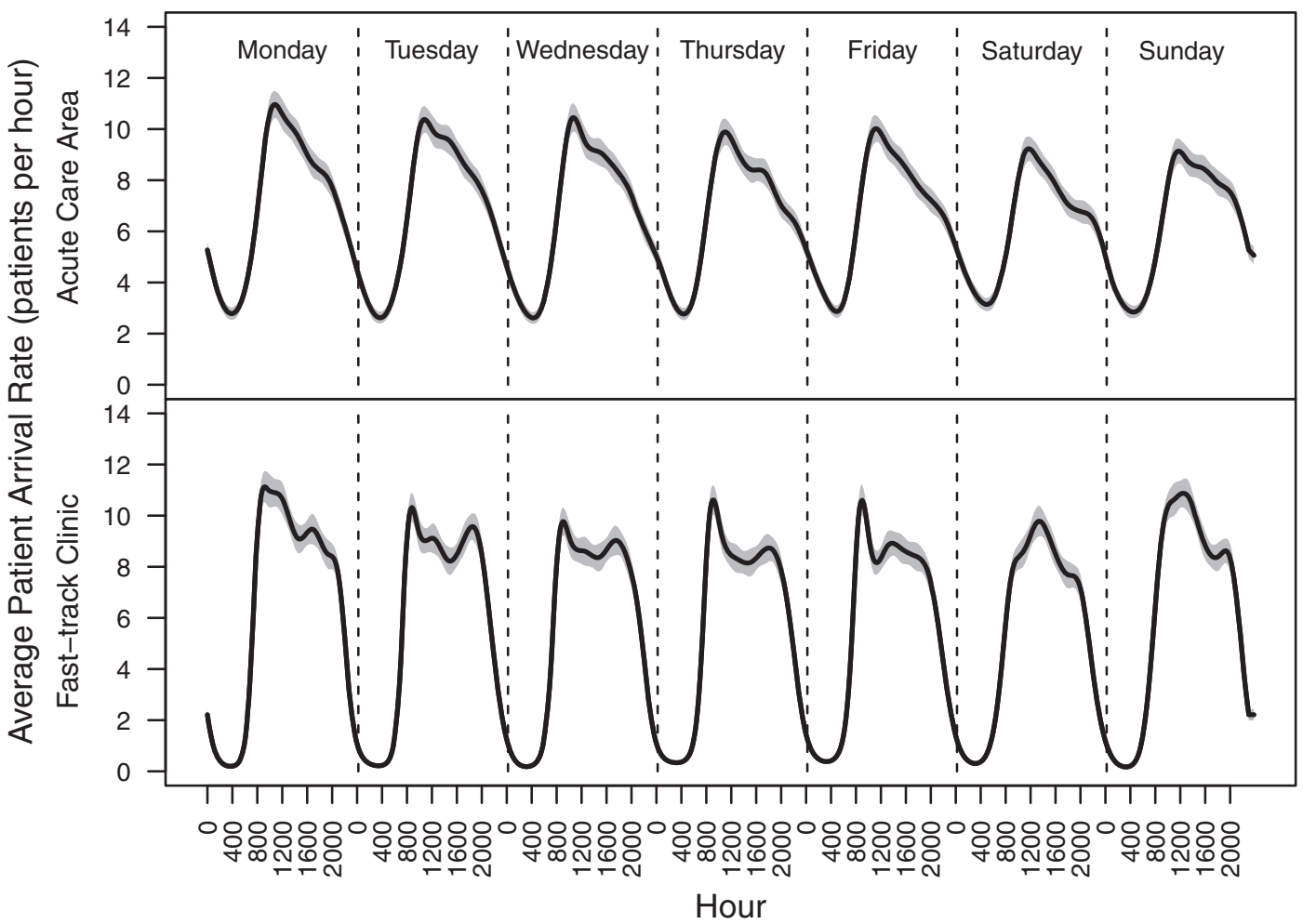

Figure 1. A comparison of fitted patient arrival rates in the acute care area and fast-track clinic by day of the week with $95 \%$ confidence bands. 
final 3 hours of the shift, acute care physicians will see patients in the fast-track clinic. The physician working the 2359 shift sees new patients for the entire 8-hour shift in both the acute care area and the fast-track clinic. The shifts in the acute care area at the TBRHSC ED are organized this way to minimize patient transfer of care at the end of each shift and to ensure that patient flow in the fast-track clinic is maintained during peak patient arrival periods.

\section{Model}

We developed a mixed-integer programming model that generates a schedule of optimal shift start times for the acute care area and fast-track clinic. The model accounts for the movement of physicians from the acute care area to the fast-track clinic in the last 3 hours of an 8-hour shift. The model is a series of linear equations that define when physicians can be scheduled, the total number of physicians available per day, and the relationship between physician productivity and patient demand. The model equations and variable definitions can be found in the Appendix. Physician productivity was estimated from hourly historical counts of ED arrival data collected from April 1, 2011, to March 31, 2012, and found to be 4.1 patients treated per hour in the acute care area, 5.9 patients treated per hour in the fast-track clinic, and 2 patients treated per hour in the fast-track clinic by the acute care physicians. Acute care physician productivity in the fast-track clinic (i.e., in the last 3 hours of each shift) was based on a physician service agreement that governs the expected physician productivity in the TBRHSC ED. The scheduling model was programmed and solved using the IBM ILOG CPLEX Optimization Studio version 12.4 .

\section{Scenarios examined}

The model developed for this study was used to compare the current physician schedule to three scenarios: 1) a revised schedule, 2) a revised schedule with one additional acute care physician, and 3) a revised schedule with one additional fast-track physician.

\section{RESULTS}

Plots of hourly totals of patient arrivals and hourly averages of patient arrivals revealed differences in patterns of patient arrivals at the acute care area and fast-track clinics (Figure 2). Consequently, these two treatment areas in the ED were analyzed separately.

For the acute care area data, exploratory analyses and comparisons of different GAMs suggested that it was not necessary to consider each weekday separately or to model separate arrival curves for weekdays versus the weekend because the patterns in the hourly arrival data were similar on average regardless of the day of the week. Hence, a model with a single daily arrival rate was estimated (see Figure 2A). It is important to note that there was a strong overlap in the confidence region for the modelled single daily patient arrival curve and those for each day of the week in Figure 1. Although the curves in Figure 1 for each day of the week were a statistically significant improvement over that of Figure 2A, the improvement was marginal and has little practical impact in terms of our OR modelling. The simple daily model, which represented all days of the week, was therefore employed in the scheduling analysis that follows.

Fast-track clinic data showed differences in patient arrival rates on weekdays versus the weekend. To

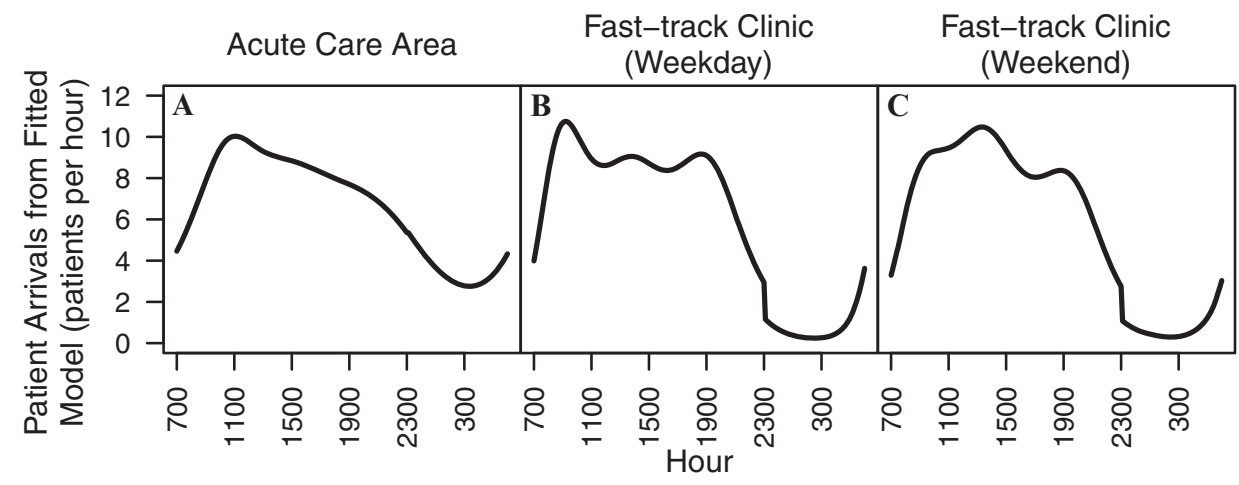

Figure 2. Fitted patient arrival rates from the generalized additive model (GAM) in the A) acute care area, B) weekday fast-track clinic, and $\mathrm{C}$ ) weekend fast-track clinic. The fitted model values were used in the planning model as the patient demand. 
account for this, the scheduling model was run with separate arrival rates for weekdays and the weekends. The fitted model for the fast-track clinic is illustrated (see Figure 2, B and C), and this model was employed for the fast-track arrivals in our scheduling analysis.

We also examined whether or not arrival rates varied on holiday weekends (defined as Friday through Monday of any holiday weekend) by testing for a multiplicative change to the estimated rates given in Figure 2. For both the acute care area and fast-track clinics, a statistically significant effect was found. The actual impact of these effects was negligible: the multiplicative factors were less than $\pm 4 \%$ (i.e., essentially no practical changes to the hourly arrival rate curves, which were measured as patients/hour). Holiday weekend effects were not included in the OR scheduling analyses.

The OR planning model improved the alignment of physicians and patients arriving at the ED as seen in the revised schedule scenario (Figure 3). Although there were no practically important differences between weekday and weekend patient arrivals at the acute care area of the ED, the two separate arrival rates in the fast-track clinic influenced the scheduling of the acute care physicians, as shown by the different weekday and weekend schedules in the revised schedule and the revised schedule with one additional acute care physician scenarios.

The planning model appears to have made marginal improvements to the physician productivity in the fasttrack clinic (Figure 4). The one notable improvement is the addition of another physician in the morning to handle the increased patient arrival rate.

Figure 5 compares the shift start times for the four scenarios along with the current schedules for both the acute care area and fast-track clinic. Generally, the physician start times were earlier than the current schedule for both the acute care area and fast-track clinics. The earlier start times would align physicians with the high patient arrival rates in the morning.

In the revised schedule scenario, the planning model improved the total physician productivity by $19 \%$ by decreasing unmet patient demand (Table 1). The addition of a physician to the acute care area and fast-track clinics further reduced the unmet patient demand by $39 \%$ and $69 \%$, respectively.

\section{DISCUSSION}

It appears possible to generate optimal shift schedules that align physician productivity with patient arrivals in the ED. Although the results of the revised schedule scenario (i.e., a 19\% reduction in unmet patient demand) are promising, aligning physician productivity with patient demand is only one strategy for increasing patient throughput in the ED. ${ }^{15}$ Although other strategies may have a greater impact on patient flow in the ED compared to the one investigated in this study, few can be implemented with minimal cost or as quickly. The benefit of this strategy is that the total number of physicians does not change, there is no change to the pattern of patient flow, and this strategy has little effect on other staff or resources.

The development of the physician shift schedule in this study is the first step in physician scheduling in the ED. Allocation of individual physicians to each shift (e.g., over the course of a month) is a secondary problem, which is complicated by rules that govern the minimum time permitted between shifts, the number of consecutive days allowed, the number and timing of days off, and equity in allocating day, night, and weekend shifts among eligible physicians. ${ }^{21}$ The use of OR planning models in some studies has not only improved the quality of physician schedules but also significantly reduced the schedule preparation time.

The model presented in this study schedules a set of predetermined shifts (i.e., 8-hour shifts were created with starting times from 0800 to 2359 and programmed into the model) to best align physician productivity and patient arrivals at the ED. The predetermined shifts can be designed from a physician perspective to reduce the physiologic, psychological, and social effects of shift work. ${ }^{22}$ If ED physicians choose to modify their workflow pattern (i.e., an 8hour shift with the first 4 hours in the acute care area and the last 3 hours in the fast-track clinic), the revised shift structure could easily be entered into the model, producing a new shift schedule.

Our results suggest that the revised schedule with one additional fast-track physician scenario would have the greatest impact on the ED. Although this scenario had the largest effect on the unmet patient demand, the addition of an acute care physician would be most beneficial to the ED. Because patients in the fast-track clinic have a lower acuity, anecdotal evidence suggests that physicians can increase productivity to treat these patients more quickly. While in the acute care area, many of the patients require more resources, and an additional physician may have the greatest impact on patient throughput and increase overall ED efficiency. 


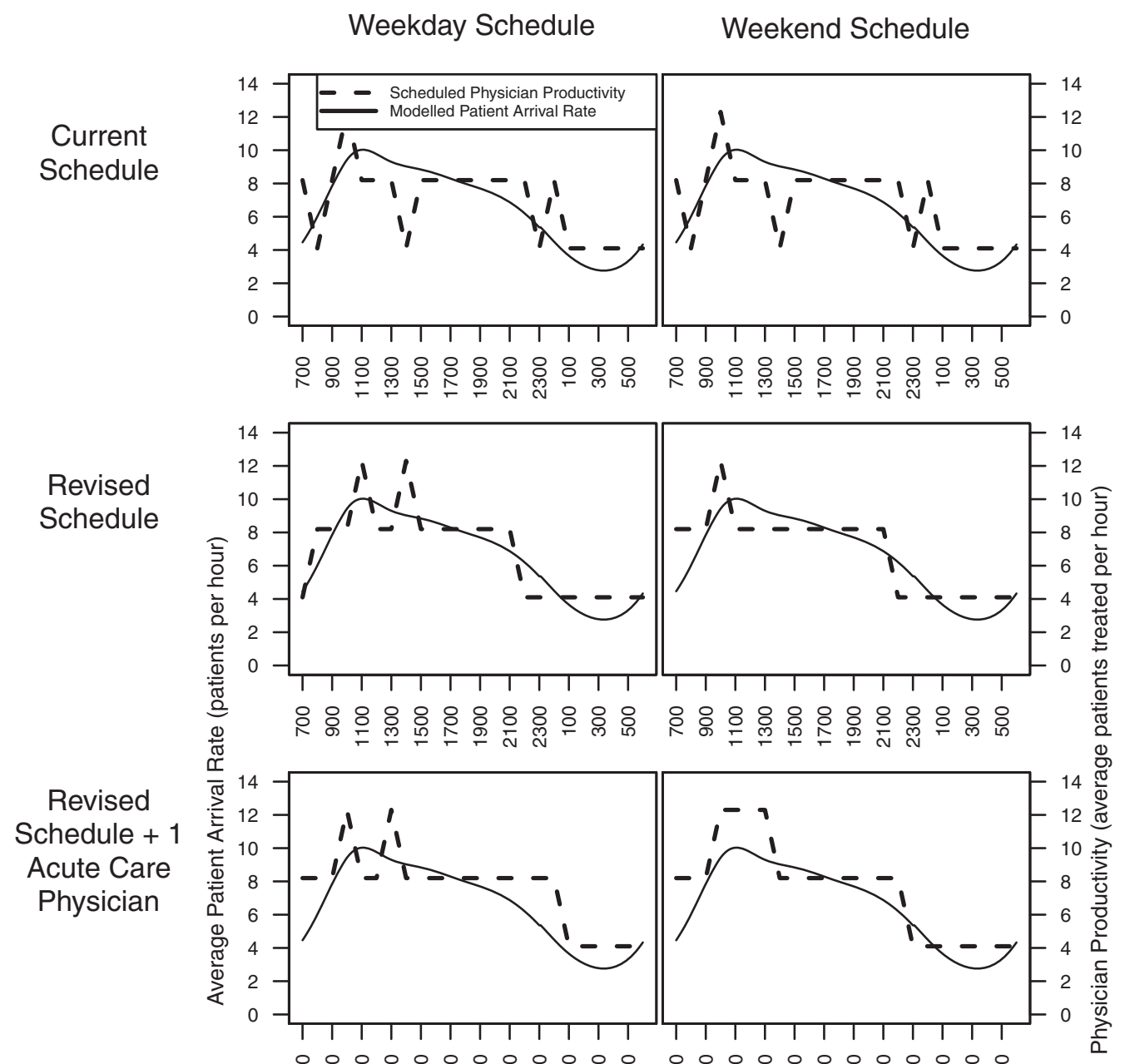

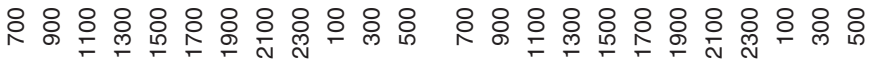

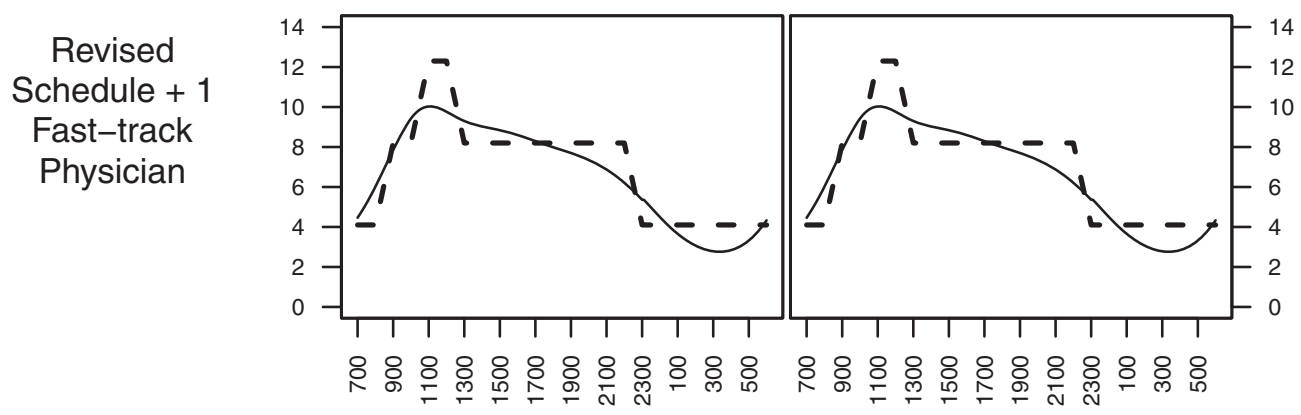

Hour

Figure 3. Acute care area results. The solid line represents the fitted patient arrival rates (i.e., average number of patients per hour) from the generalized additive model. The dashed lines show the scheduled physician productivity (i.e., the average number of patients treated per hour) in the acute care area for the four scenarios with weekday versus weekend schedules.

\section{LIMITATIONS}

Our preliminary analyses suggested that there may be differences in acute care area and fast-track clinic arrival rates over holiday weekends. We used a simple multiplicative scaling effect (i.e., the base arrival rate times a percent increase or decrease). Although the estimated effect was statistically significant, it had no practically important impact on the arrival rates. This distinction is comparable to statistical versus clinical significance in other medical studies. We considered the multiplicative effect only because of limited data 


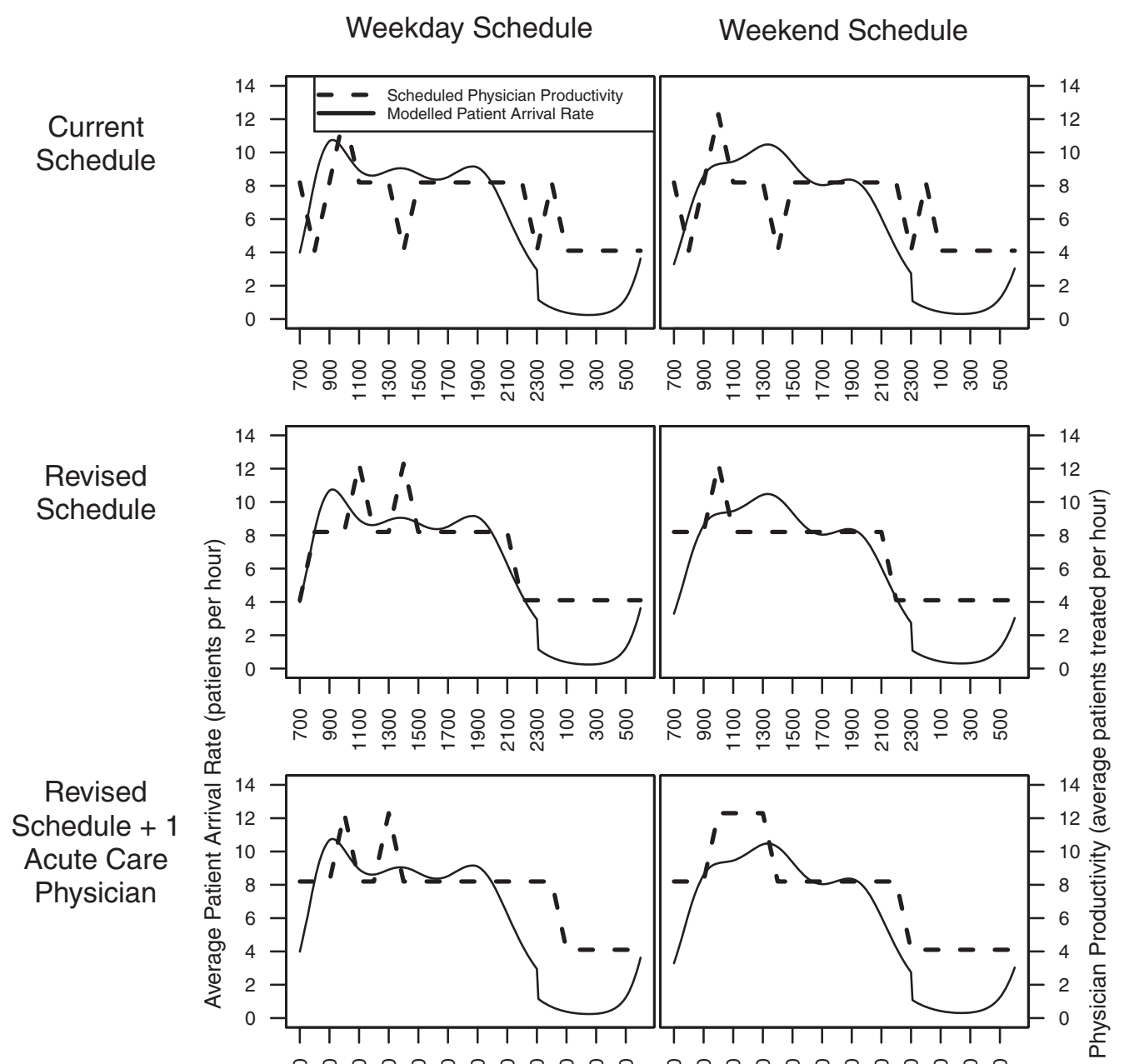

\section{Revised Schedule +1 \\ Fast-track \\ Physician}

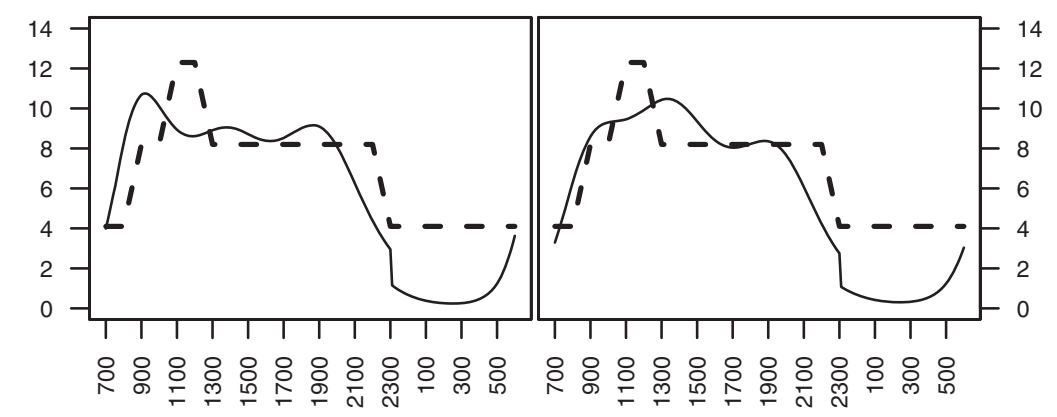

Hour

Figure 4. Fast-track clinic results. The solid line represents the fitted patient arrival rates (i.e., average number of patients per hour) from the generalized additive model. The dashed lines show the scheduled physician productivity (i.e., the average number of patients treated per hour by both the dedicated fast-track physician and the acute care physician at the end of their shift) in the fast-track clinic for the four scenarios with weekday versus weekend schedules.

(i.e., just 1 year of patient arrivals) for holiday weekends. It is possible that patterns in patient arrivals vary by more than a simple multiplicative factor on holiday weekends and may be related to seasonal patterns. Analysis of ED arrival data over longer time horizons would permit the investigation of these more complicated effects.

In the ED, patient arrival times and physician productivity can be highly variable. Our modelling used the average rates for these two processes. A more 


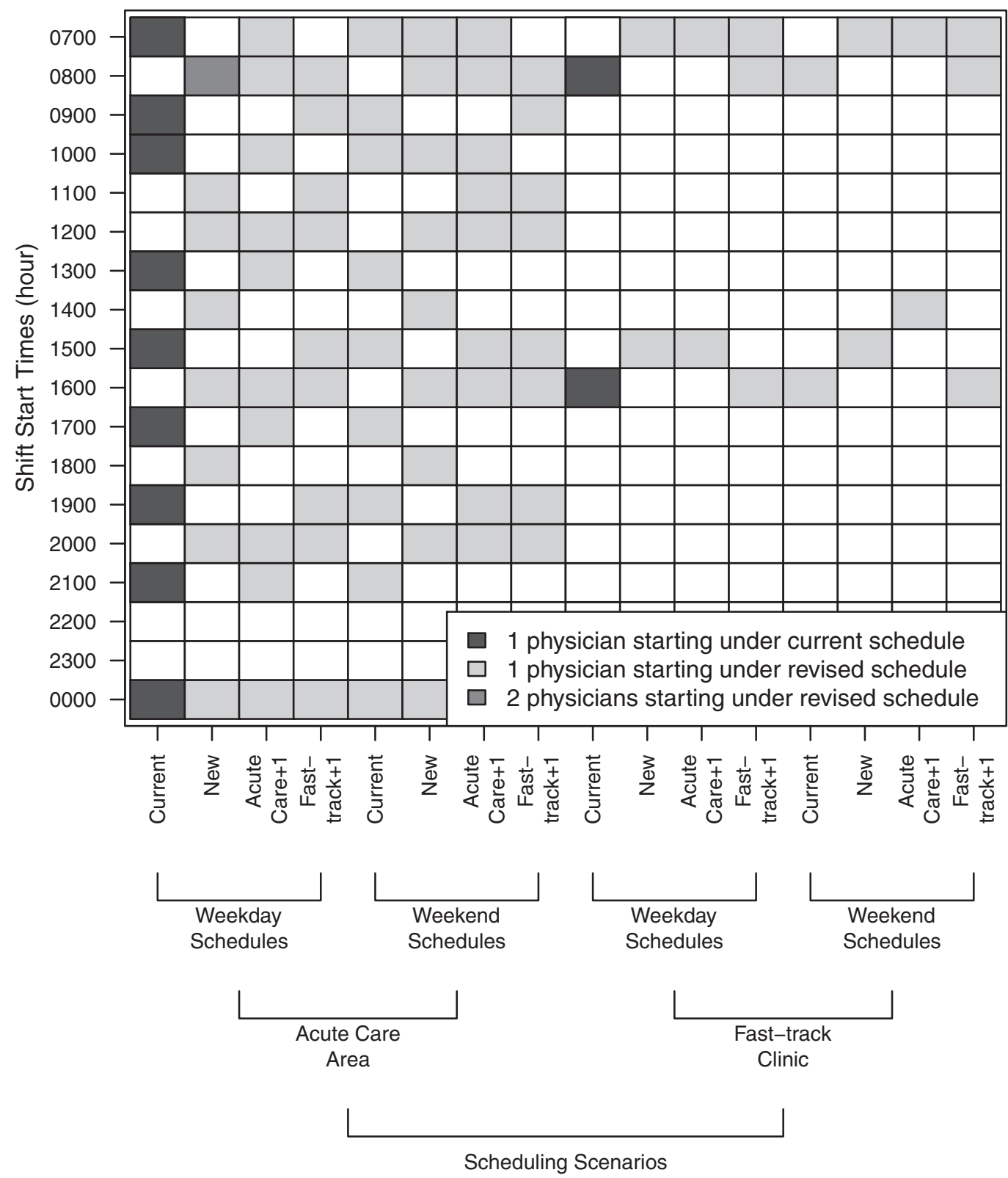

Figure 5. Each box represents a potential shift start time, with the shaded boxes indicating a start time scheduled by the planning model. The $y$-axis represents the shift start times, and the $x$-axis represents the four scenarios examined for the weekday versus weekend schedules in the acute care area and fast-track clinic. The darkest boxes show the current schedule, whereas the lighter boxes show the new schedule for each of the scenarios examined. Note that in the Revised scenario in the second column, two physicians start at the same time (i.e., at 0800 hours).

complicated OR modelling technique (e.g., computer simulation modelling or stochastic programming) would be required to incorporate the variability observed in the actual ED in the shift scheduling. The average values used in our modelling framework offer a good estimate of the actual patient arrival rates, and our decision-making tool would be quicker and easier to implement for shift scheduling in the ED than several other OR techniques.

\section{CONCLUSION}

The planning model developed in this study produced a revised schedule that improved the alignment of physician staffing with patient arrivals. The physician workflow pathway in the ED created a unique problem where acute care physicians were responsible for higher-acuity patients at the beginning of the shift and lower-acuity patients at the end. The model was 
Table 1. A summary of unmet patient demand* per day for weekdays and weekends in the 4 scenarios examined

\begin{tabular}{llc}
\hline \multirow{2}{*}{ Scenario } & \multicolumn{2}{c}{ Schedule } \\
\cline { 2 - 3 } & \multicolumn{1}{c}{ Weekday } & Weekend \\
\hline Current schedule & 34.9 & 31.2 \\
Revised schedule & $28.2\left(19 \%^{\dagger}\right)$ & $25.2(19 \%)$ \\
Revised + 1 acute care physician & $21.3(39 \%)$ & $18.9(39 \%)$ \\
Revised + 1 fast-track physician & $10.8(69 \%)$ & $9.9(68 \%)$ \\
\hline
\end{tabular}

*That is, the average number of patients arriving in the emergency department beyond the average physician productivity.

${ }^{\dagger}$ These values denote the percent decrease in unmet demand for each scenario developed using the planning model compared to the current schedule.

able to account for this dual responsibility and incorporate it in the planning. Users of these models need to recognize that although they can improve efficiency through better resource allocation and faster generation of schedules, the scenario with the greatest impact on unmet patient demand (i.e., revised schedule with one additional fast-track physician) may not be the best decision when other factors are considered.

Acknowledgements: We would like to thank the IBM Academic Initiative for use of the IBM ILOG CPLEX Optimization Studio.

Competing interests: The Northern Ontario School of Medicine supported this research through its medical student research awards. This research was also supported, in part, by the Natural Sciences and Engineering Research Council of Canada through its Discovery Grants program.

\section{REFERENCES}

1. Rowe BH, Bond K, Ospina MB, et al. Frequency, determinants, and impact of emergency department overcrowding in Canada. Technology Report No. 67.3. Ottawa (ON): Canadian Agency for Drugs and Technologies in Health; 2006.

2. Canadian Association of Emergency Physicians/National Emergency Nurses Affiliation. Joint position statement: access to acute care in the setting of emergency department overcrowding. Can 7 Emerg Med 2003;5:81-6.

3. Ontario Ministry of Health and Long-Term Care. Ontario wait times, emergency room wait times - emergency room targets 2012. Available at: http://www.health.gov.on.ca/en/pro/programs/ waittimes/edrs/targets.aspx (accessed June 26, 2012).

4. Derlet RW, Richards JR. Overcrowding in the nation's emergency departments: complex causes and disturbing effects. Ann Emerg Med 2000;35:63-8, doi:10.1016/S01960644(00)70105-3.

5. Bond $\mathrm{K}$, Ospina $\mathrm{M}$, Blitz $\mathrm{S}$, et al. Interventions to reduce overcrowding in emergency departments. Ottawa (ON): Canadian Agency for Drugs and Technologies in Health; 2006.
6. Browne G, Lam L, Giles H, et al. The effects of a seamless model of management on the quality of care for emergency department patients. I Qual Clin Pract 2000;20:120-6, doi:10.1046/j.1440-1762.2000.00377.x.

7. Bucheli B, Martina B. Reduced length of stay in medical emergency department patients: a prospective controlled study on emergency physician staffing. Eur 7 Emerg Med 2004;11:29-34, doi:10.1097/00063110-200402000-00006.

8. Fernandes CM, Christenson JM. Use of continuous quality improvement to facilitate patient flow through the triage and fast-track areas of an emergency department. 7 Emerg Med 1995;13:847-55, doi:10.1016/0736-4679(95)02023-3.

9. Krakau I, Hassler E. Provision for clinic patients in the ED produces more nonemergency visits. Am 7 Emerg Med 1999; 17:18-20, doi:10.1016/S0735-6757(99)90006-2.

10. Lau FL, Leung KP, Cocks RA. Waiting time in an urban accident and emergency department - a way to improve it. 7 Accid Emerg Med 1997;14:299-303, doi:10.1136/emj.14.5.299.

11. Rotstein Z, Wilf-Miron R, Lavi B, et al. Management by constraints: considering patient volume when adding medical staff to the emergency department. Isr Med Assoc 7 2002; 4:170-3.

12. Vilke GM, Brown L, Skogland P, et al. Approach to decreasing emergency department ambulance diversion hours. 7 Emerg Med 2004;26:189-92, doi:10.1016/j.jemermed. 2003.07.003.

13. Winston WL. Operations research: applications and algorithms. Singapore: Duxbury Press; 2003.

14. Izady N, Worthington D. Setting staffing requirements for time dependent queueing networks: the case of accident and emergency departments. Eur 7 Oper Res 2012;219:531-40, doi:10.1016/j.ejor.2011.10.040.

15. Centeno MA, Giachetti R, Linn R, et al. A simulation-ILP based tool for scheduling ER staff. In: Chick S, Sánchez PJ, Ferrin D, et al, editors. Proceedings of the 2003 Winter Simulation Conference New Orleans (LA): IFNORMS Simulation Society; 2003. p. 1930-8. Available at: http:// informs-sim.org/wsc03 papers/251.pdf.

16. Coats TJ, Michalis S. Mathematical modelling of patient flow through an accident and emergency department. Emerg Med 7 2001;18:190-2, doi:10.1136/emj.18.3.190.

17. Schull MJ, Vermeulen M. Ontario's alternate funding arrangements for emergency departments: the impact on the emergency physician workforce. Can 7 Emerg Med 2005; $7: 100-6$

18. Gurrin LC, Scurrah KJ, Hazelton ML. Tutorial in biostatistics: spline smoothing with linear mixed models. Statist Med 2005;24:3361-81, doi:10.1002/sim.2193.

19. Wood SN. Generalized additive models: an introduction with $R$. Boca Raton, (FL): Chapman \& Hall/CRC; 2006.

20. Core Team. R: a language and environment for statistical computing. Vienna: R Foundation for Statistical Computing; 2012. Available at: http://www.R-project.org.

21. Carter MW, Lapierre SD. Scheduling emergency room physicians. Health Care Manage Sci 2001;4:347-60, doi:10. 1023/A:1011802630656.

22. Knauth P. Designing better shifts systems. Appl Ergon 1996; 27:39-44, doi:10.1016/0003-6870(95)00044-5. 


\section{Appendix}

\section{Model parameters}

$i$ denotes treatment areas (i.e., $1=$ acute care area and 2 = fast-track clinic).

$j$ denotes time period (i.e., $1=0700 \mathrm{hrs}, 2=0800 \mathrm{hrs}$, $3=0900$ hrs, ..., $24=0600$ hrs).

$k$ denotes each physician (i.e., $1=$ physician $1,2=$ physician $2, \ldots, \mathrm{K}$ ), where $\mathrm{K}$ is the total number of physicians available to work each day.

$l$ denotes all of the possible shift schedule start times (i.e., $1=0700$ hrs, $2=0800$ hrs, ..., $18=2400$ hrs). $m$ denotes the physician's duty in the ED (i.e., $1=$ acute care area physician, 2 = fast-track clinic physician, and 3 = acute care physician in fast-track clinic).

\section{Decision variables}

$U_{n M e t D e m a n d}{ }_{i j}=$ the difference between physician productivity and patient demand in treatment area $i$ in time period $j$.

Doctor $_{i k l}=$

$\left\{\begin{array}{l}1 \text { if treatment area } i \text {, physician } k \text {, is assigned to shift } l \\ 0 \text { otherwise }\end{array}\right.$

PhysicianProductivity $y_{m j}=$ the total patients treated by the physician with duty $m$ in time period $j$.

\section{State variables}

Schedule $_{m l j}=$ a matrix of 1's and 0's, where 1 denotes when a physician with duty $m$ will accumulate new patients to treat for shift $l$, in time period $j$.

HourlyProductivity $_{m}=$ the number of patients treated per hour by the physician with duty $m$.

PatientArrival $_{i j}=$ the average number of patients arriving in the ED for treatment area $i$ in time period $j$.
The objective function of the model (equation 1) minimized the difference between physician productivity (i.e., the average number of patients treated per hour) and patient demand in the ED.

$$
\text { Minimize } \quad \sum_{i j} \text { UnMetDemand }_{i j}
$$

The first constraint (equation 2) ensures that each physician is assigned to a single shift each day.

$$
\sum_{i} \sum_{k} \text { Doctor }_{i k l}=1 \quad \forall l
$$

The second constraint (equation 3) sums the hourly physician productivity (i.e., average patients treated per hour) for all physicians scheduled to work in a particular time period for each duty in the ED.

$$
\begin{aligned}
& \text { PhysicianProductivity }_{m j}=\sum_{k} \sum_{l} \text { Doctor }_{m k l} \times \\
& \text { Schedule }_{m l j} \times \text { HourlyProductivity }_{m} \quad \forall m, j,
\end{aligned}
$$

The third constraint (equation 4) requires that the physician productivity and unmet patient demand exceed the average number of patients arriving at the ED during each time period. The UnMetDemand ${ }_{\mathrm{ij}}$ decision variable prevents an infeasible model when physician productivity does not exceed the average patient arrival. Physician productivity was limited by the total number of physicians available to work on given day.

$\sum_{m}$ PhysicianProductivity $_{m}+\sum_{i}$ UnMetDemand $_{i j}$

$\geq \sum_{i}$ PatientArrival $_{i j} \quad \forall j$,

The final constraint (equation 5) requires that the physician productivity is greater than 1 for all time periods in the acute care area and ensures that a physician is always scheduled.

$$
\text { PhysicianProductivity }_{1 j} \geq 1 \quad \forall j .
$$

